\section{Beurteilung von klinisch-chemischen Befunden}

C. Vidal ${ }^{1}$ und W.-R. Külpmann ${ }^{2}$

${ }^{1}$ Landeskriminalamt Niedersachsen, Dezernat 53 „Chemie“, Hannover, Deutschland

${ }^{2}$ Hannover, Deutschland

Synonym(e) Befundbeurteilung

Englischer Begriff evaluation of clinical chemical findings

Beschreibung Klinisch-chemische Befunde werden beurteilt, um Folgerungen für Diagnose, Krankheitsverlauf, Prognose und Therapie abzuleiten.
Bei der Beurteilung ist zu bedenken, dass pathognomonische Befunde selten sind. Vielmehr können einem Befund meist verschiedene Ursachen/Krankheiten zugrunde liegen. Die Ausprägung des Befundes kann unterschiedlich stark und vom Stadium der Erkrankung abhängig sein. Der Einfluss von Pharmaka und anderer Therapiemaßnahmen ist zu berücksichtigen.

\section{Literatur}

Büttner J, Stamm D (1995) Ärztliche Verwendung von klinischchemischen Befunden. In: Greiling H, Gressner AM (Hrsg) Lehrbuch der Klinischen Chemie und Pathobiochemie, 3. Aufl. Schattauer Verlag, Stuttgart, S 96-111 